\title{
ASSESSMENT OF FLUID RESPONSIVENESS IN PATIENTS WITH ACUTE CIRCULATORY FAILURE USING ECHOCARDIOGRAPHY
}

\author{
By
}

\author{
Abd Allah Mahmoud El-Shennawy*, Ahmed Mohammed Salah El-Din \\ Ahmed**, Mostafa Ahmed Roshdy* and Atef Abou El-Fotouh Ibrahim* \\ Departments of *Internal Medicine and ** cardiology,Faculty of Medicine, Al-Azhar \\ University \\ Corresponding author: Abd Allah Mahmoud El-Shennawy \\ E-mail: www.abdallh911633@gmail.com
}

\begin{abstract}
Background: Predicting fluid responsiveness, the response of stroke volume (SV) to fluid loading, is a relatively novel concept that aims to optimize circulation, and as such organ perfusion, while avoiding futile and potentially deleterious fluid administrations in critically ill patients. Dynamic parameters have shown to be superior in predicting the response to fluid loading compared with static cardiac filling pressures. Passive leg raising (PLR) as a means to alter biventricular preload in combination with subsequent measurement of the change in stroke volume can provide a fast and accurate way to guide fluid management in a broad population of critically ill patients.
\end{abstract}

Objective: To assess the fluid responsiveness in patients with acute circulatory failure using left ventricular outflow variation by $2 \mathrm{D}$ echocardiography and inferior vena cava diameter.

Patients and Methods: After departmental ethics committee approval and patient consents were obtained, 40 patients included in this work with shock not on mechanical ventilation who were admitted to Critical Care unit of Internal Medicine Department in Al-Hussein Hospital, Al-Azhar University, and The study was carried out during the period from April 2019 to August 2020, 30 patients were responder, and 10 patients were not responder. All patients were subjected to complete history taking, complete physical examination including: arterial blood pressure with mean arterial pressure (MAP) calculation, heart rate (HR), respiratory rate (RR), body temperature $\left({ }^{\circ} \mathrm{C}\right)$. Laboratory investigations included complete blood count (CBC), liver function tests, renal function tests and arterial blood gases (ABGs). In addition, echocardiographic assessment was performed, the left ventricular outflow tract velocity time integral (LVOT) VTI was recorded classically by pulsed wave doppler across LVOT on a 5-chamber apical view, maximum and minimum inferior vena caval DIVC values over a single respiratory cycle were measured before and after (PLR).

Results: In the two groups (responder and not responder), 18 (45\%) were males and $22(55 \%)$ were females. 22 (55\%), 20 (50\%), 13 (32.5\%), 17 (42.5\%), 9(22.5\%) were patients with diabetic (DM), hypertensive (HTN), chronic kidney disease (CKD), smoking and on vasoactive drugs respectively, There was no significant difference between the two groups as regard hemodynamic data on admission including temperature, respiratory rate, and pulse rate, There were significant differences between the two groups as regard hemoglobin (Hb), alanine transaminase (ALT), aspartate transaminase (AST) on admission.

By echocardiographic parameters, change of velocity time integral $\Delta$ VTI \% showed significant difference between the two groups with the areas under the curve 0.800 , at the cutoff value 3.409 . The sensitivity was 90.0, specificity was 70.0, PPV $90.0 \%$, and NPV $70.0 \%$ in predict the response.

Conclusion: Careful management of volume status and fluid administration is an important determinant of outcomes of the critically ill patients. The change in stroke volume displayed predicted fluid responsiveness 
in shocked not mechanically ventilated patients with an acceptable sensitivity and specificity than IVC collapsibility Index.

Key words: Fluid responsiveness, VTI, passive leg raising, endoscopic technique, interlaminar approach, lumbar discectomy, minimally invasive.

\section{INTRODUCTION}

Fluid resuscitation remains the cornerstone of treatment for patients with acute circulatory failure. Inappropriate administration of fluids has deleterious effects, including volume overload, systemic and pulmonary edema, and limitation of oxygen diffusion to tissues, thereby leading to increased tissue hypoxia (Hu et al., 2013 and Pinsky, 2015).

One method routinely used to evaluate intravascular volume in hypotensive patients uses hemodynamic response to a fluid challenge can be monitored clinically by heart rate, blood pressure, pulse pressure, and urine output or by invasive monitoring with the measurements of the right atrial pressure (RAP), pulmonary artery occlusion pressure (PpAO), and cardiac output (Mackenzie and Noble, 2014).

Hemodynamic parameters, such as pleth variability index and stroke volume variation, may better predict fluid responsiveness. However, the measurement of these parameters requires invasive procedures and special monitoring equipment, limiting their clinical application (Pinsky, 2015).

Studies have shown that some parameters may be related to volume status. The traditional static parameters, such as intrathoracic blood volume index, pulmonary wedge pressure, pulse pressure variation, and central venous pressure, have been proved not to be related to patient's a volume status (Hu et al., 2013). At same time with the spread of critical care echocardiography, several echocardiographic indices of fluid responsiveness have been proposed in spontaneous and mechanically ventilated patients (Bentzer et al., 2016).

The present work aimed to assess the fluid responsiveness in patients with acute circulatory failure using left ventricular outflow variation by 2D echocardiography and inferior vena cava diameter.

\section{PATIENTS AND METHODS}

This prospective observational investigation study was conducted on 40 adult patients divided into two groups

- Responders group (R): 30 shocked patients with SV post PLR test $\geq 10 \%$.

- Non-responders group (NR): 10 shocked patients with SV post PLR test $<10 \%$.

Patients were admitted to the Critical Care unit of Internal Medicine Department in Al-Hussein Hospital, AlAzhar University with the diagnosis of shock. Approval of the medical ethics committee of Al-Azhar Faculty of Medicine had been taken. An informed consent from patient or patients' next of kin had been taken before enrollment to the study.

The study was carried out during the period from April 2019 to August 2020. 
Inclusion criteria: Age between (18-70) years old, spontaneously breathing patients, and patients diagnosed to have acute circulatory failure.

Exclusion criteria: Incarceration, pregnancy, amputation or severe lower limb ischemia, and contraindication to a passive leg raise (PLR) maneuver (e.g. elevated intracranial pressure, tamponade, acute aortic dissection), resuscitation for more than $48 \mathrm{~h}$.

- All patients included in the study were subjected on admission to complete history taking, complete physical examination including arterial blood pressure with mean arterial pressure (MAP) calculation, heart rate $(\mathrm{HR})$, respiratory rate $(\mathrm{RR})$, and body temperature $\left({ }^{\circ} \mathrm{C}\right)$.

- Laboratory investigations: Complete blood count (CBC), serum creatinine $(\mathrm{Cr})(\mathrm{mg} / \mathrm{dl})$, total bilirubin and arterial blood gases (ABGs),

- Echocardiographic assessment was performed: The left ventricular outflow tract (LVOT) VTI was recorded, The IVC was visualized and IVC collapsibility index was calculated from the following formula:

- A standard passive leg rising test was done by placing a patient in a semirecumbent position for three minutes, then laying the patient supine with the $\frac{\text { IVCexpiratorydiameter-IVCinspiratorydiameter }}{\text { IVCexpiratorydiameter }} \times 100$

legs elevated to 45 degrees for three minutes and measuring stroke volume (SV), velocity time integral of left ventricular outflow tract (VTI (LVOT)), inferior vena caval (IVC) collapsibility index, and cardiac output before and immediately (1-3 minutes) following the PLR maneuver (Bendjelid and Romand, 2003).

- Statistical analysis of data by IBM computer using statistical package for the social sciences (SPSS) version 20: unpaired (Independent) t-test to compare quantitative variables between groups and if not normally distributed sample we used Mann-Whitney U. Agreement of the predictive with the responsiveness was expressed in sensitivity, specificity, positive predictive value, negative predictive value and accuracy. Receiver operating characteristic curve (ROC) was plotted to analyze a recommended cutoff, significance test results are quoted as two-tailed probabilities. Significance of the obtained results was judged at the $5 \%$ level.

\section{RESULTS}

There was a significant relationship between fluid responsiveness and $\mathrm{Hb}$, ALT, AST as p values were 0.001, 0.006, and 0.007 respectively, while no significant relationship between fluid responsiveness, and other laboratory parameters or present clinical data (Tables 1 and 2). 
Table (1): Relation between Clinical and lab Parameters and fluid responsiveness $($ Mean \pm S.D)

\begin{tabular}{|c|c|c|c|}
\hline \multicolumn{1}{|c|}{ Groups } \\
$\begin{array}{c}\text { Clinical and } \\
\text { Lab. Parameters }\end{array}$ & $\begin{array}{c}\text { Responder group. } \\
\text { " } \mathrm{n}=30 \text { " }\end{array}$ & $\begin{array}{c}\text { Non responder group. } \\
\text { " } \mathrm{n}=10 "\end{array}$ & $\mathrm{P}$ \\
\hline Age (years) & $59.6333 \pm 11.08426$ & $50.6667 \pm 5.83730$ & 0.913 \\
\hline mean BP (mm/Hg) & $52.5000 \pm 10.40143$ & $103.9000 \pm 24.42426$ & 0.601 \\
\hline Pulse (beat/mint) & $99.3000 \pm 18.61062$ & $37.2200 \pm 0.12293$ & 0.535 \\
\hline Temp. $\left({ }^{\circ} \mathrm{C}\right)$ & $37.4000 \pm 0.34039$ & $28.3000 \pm 3.52924$ & 0.112 \\
\hline R.R (cycle/mint) & $30.7667 \pm 3.68298$ & $6.6000 \pm 10.29779$ & 0.072 \\
\hline PH & $7.2957 \pm 0.12249$ & $7.2970 \pm 0.12320$ & 0.976 \\
\hline SVC SO2 (\%) & $0.6307 \pm 0.14729$ & $12.3100 \pm 2.41682$ & 0.574 \\
\hline Hb (g/dL) & $9.2767 \pm 2.16073$ & $15.0100 \pm 9.07995$ & 0.001 \\
\hline
\end{tabular}

Table (2): Relation between Clinical and lab Parameters and fluid responsiveness $($ Mean \pm S.D)

\begin{tabular}{|c|c|c|c|c|}
\hline \multirow[t]{2}{*}{ Groups } & \multirow[b]{2}{*}{$\begin{array}{l}\text { Responder group. } \\
\text { " } \mathrm{n}=30 \text { " }\end{array}$} & \multirow{2}{*}{$\begin{array}{l}\text { Non responder } \\
\text { group. } \\
\text { "n=10" }\end{array}$} & \multicolumn{2}{|c|}{$\begin{array}{l}\text { If not normally } \\
\text { Distributed }\end{array}$} \\
\hline & & & $\begin{array}{c}\text { Mann- } \\
\text { Whitney } \\
\text { U }\end{array}$ & $\begin{array}{l}\text { Asymp. } \\
\text { Sig. (2- } \\
\text { tailed) }\end{array}$ \\
\hline $\operatorname{TLC}\left(\times 10^{3} / \mu 1\right)$ & $15.4967 \pm 11.99340$ & $15.0100 \pm 9.07995$ & 149.000 & 0.975 \\
\hline ALT (U/C) & $30.0200 \pm 25.26306$ & $405.000 \pm 719.07255$ & 77.500 & 0.024 \\
\hline AST (U/C) & $69.6667 \pm 86.63532$ & $524.600 \pm 890.05233$ & 94.000 & 0.080 \\
\hline S.CR (mg/dL) & $3.4880 \pm 2.71850$ & $2.8100 \pm 2.03822$ & 135.500 & 0.650 \\
\hline UREA (mg/dL) & $132.7733 \pm 64.54376$ & $123.6400 \pm 70.36028$ & 132.000 & 0.574 \\
\hline $\mathrm{CVP}(\mathrm{cm} / \mathrm{H} 2 \mathrm{O})$ & $4.2667 \pm 3.86793$ & $6.6000 \pm 10.29779$ & 127.500 & 0.477 \\
\hline $\mathrm{HCO} 3(\mathrm{mmol} / \mathrm{L})$. & $18.1433 \pm 5.69807$ & $19.0600 \pm 4.49820$ & 137.500 & 0.696 \\
\hline $\begin{array}{c}\text { LACTATE } \\
(\mathrm{mmol} / \mathrm{L})\end{array}$ & $2.9600 \pm 1.39101$ & $2.8400 \pm 2.88798$ & 105.000 & 0.159 \\
\hline
\end{tabular}

There was a significant relationship between fluid responsiveness from one hand and $\triangle$ VTI $\%$ on other hand as $\mathrm{p}$ value 0.001 (Table 3). 
Table (3): Relation between echocardiographic parameters and fluid responsiveness (Mean \pm S.D)

\begin{tabular}{|c|c|c|c|c|}
\hline \multirow[b]{2}{*}{$\begin{array}{l}\text { Echocardiographic } \\
\text { parameters }\end{array}$} & \multirow{2}{*}{$\begin{array}{l}\text { Responder } \\
\text { group. } \\
\text { "n=30" }\end{array}$} & \multirow{2}{*}{$\begin{array}{l}\text { Non responder } \\
\text { group. } \\
\text { "n=10" }\end{array}$} & \multicolumn{2}{|c|}{$\begin{array}{l}\text { If not normally } \\
\text { distributed }\end{array}$} \\
\hline & & & $\begin{array}{c}\text { Mann- } \\
\text { Whitney } \\
\text { U }\end{array}$ & $\begin{array}{l}\text { Asymp. } \\
\text { Sig. (2- } \\
\text { tailed) }\end{array}$ \\
\hline Pre-VTI $(\mathrm{cm})$ & $20.37 \pm 6.67$ & $20.14 \pm 7.30$ & 150 & 1.000 \\
\hline Post-VTI $(\mathrm{cm})$ & $22.84 \pm 7.02$ & $19.56 \pm 8.93$ & 107.500 & 0.184 \\
\hline$\Delta \mathrm{VTI}(\%)$ & $\begin{array}{l}13.62 \pm \\
12.63 \%\end{array}$ & $3.59 \pm 16.23 \%$ & 60.000 & $0.005^{*}$ \\
\hline Pre-IVC Exp. Diameter (mm) & $18.31 \pm 4.90$ & $20.51 \pm 6.42$ & 119.000 & 0.333 \\
\hline $\begin{array}{c}\text { Pre-IVC Insp. Diameter } \\
(\mathrm{mm})\end{array}$ & $11.52 \pm 5.33$ & $14.25 \pm 7.66$ & 113.500 & 0.254 \\
\hline $\begin{array}{l}\text { Post-IVC Exp. Diameter } \\
(\mathrm{mm})\end{array}$ & $19.84 \pm 5.90$ & $20.60 \pm 5.32$ & 140.500 & 0.767 \\
\hline $\begin{array}{l}\text { Post-IVC Insp. Diameter } \\
(\mathrm{mm})\end{array}$ & $12.62 \pm 6.31$ & $12.86 \pm 5.62$ & 138.500 & 0.719 \\
\hline Pre IVCCI $(\mathrm{mm})$ & $39.04 \pm 15.98$ & $34.66 \pm 19.76$ & 112.000 & 0.235 \\
\hline Post IVCCI (mm) & $38.43 \pm 18.34$ & $38.58 \pm 21.47$ & 143.000 & 0.827 \\
\hline Pre SV $(\mathrm{ml})$ & $60.56 \pm 27.20$ & $68.09 \pm 33.59$ & 126.000 & 0.453 \\
\hline Post SV $(\mathrm{ml})$ & $92.06 \pm 59.02$ & $62.55 \pm 36.37$ & 98.000 & 0.104 \\
\hline
\end{tabular}

As regards $\Delta \mathrm{VTI} \%$ (percent of change between Pre VTI and Post VTI), the areas under the curve were done, and the cut of point which can differentiate perfectly between responder and non-responders (Table 4 and Fig. 1).

\section{Table (4): Sensitivity and specificity for $\Delta$ VTI \%}

\begin{tabular}{|c|c|c|c|c|}
\hline$\Delta$ VTI \% cut of point & Sensitivity & Specificity & + PV & $-P V$ \\
\hline$>3.409090909$ & 90.00 & 70.00 & 90.0 & 70.0 \\
\hline
\end{tabular}

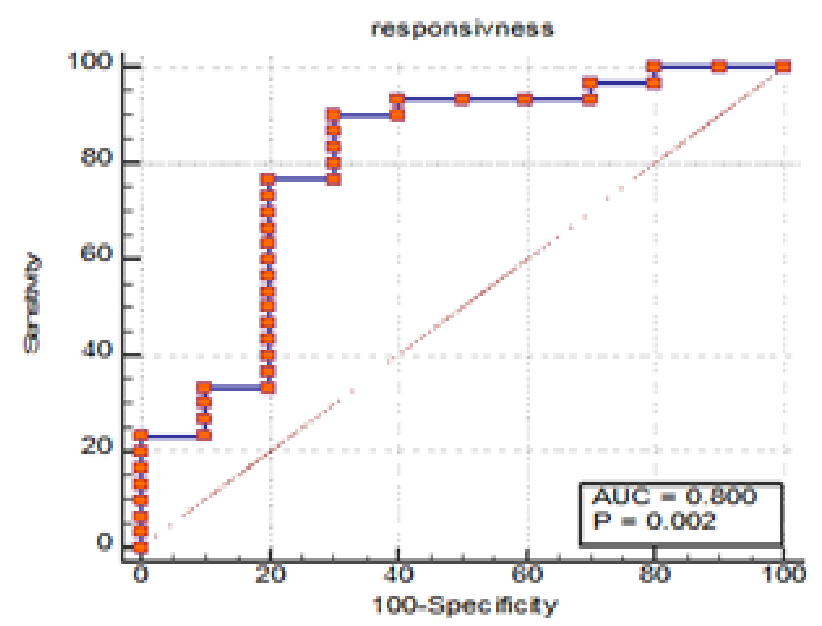




\section{Figure (1): Area under the ROC curve (AUC) for $\triangle$ VTI \%}

\section{DISCUSSION}

Forty spontaneous breathing shocked patients were studied, $45 \%$ males and $55 \%$ females. $55 \%, 50 \%, 32.5 \%, 42.5 \%$, $22.5 \%$ were patients with DM, HTN, $\mathrm{CKD}$, smoking and on vasoactive drugs respectively.

After PLR test there were significant difference change in LVOT $(\mathrm{cm})$, LVOT DIAM (mm) and SV with p values 0.002 , 0.000 , and 0.001 respectively, while no significant change in IVC DIST. (mm), IVC.COLLAB (mm), COLLAB Index with $\mathrm{p}$ values $0.073,0.445$, and 0.805 respectively.

Marik et al. (2013) defined fluid responsiveness an increase of stroke volume of $10-15 \%$ after the patient receives $500 \mathrm{ml}$ of crystalloid over 10-15 minutes SV used to define patients as fluid responder if SV increase by $10 \%$ after PLR. So, we have $75 \%$, 25\% patient fluid responder and fluid non responder respectively.

As regard the age, there was no significant difference between the two groups $(59.63 \pm 11.08$ VS. $59.20 \pm 9.67$ years). Also, there was no significant difference between responders and nonresponders as regards sex in the two groups. In agreement with Muller et al. (2012), there was no significant difference between the two groups with $\mathrm{P}$ value 0.58 .

The mean arterial blood pressure showed no significant difference between the responder and non-responder patient. This result was in agreement with Monnet et al. (2011) and Pierrakos et al. (2012) who showed that the fluid-induced changes in cardiac output are not reflected at all by the fluid-induced changes in mean arterial pressure (MAP).

In this study, the SVC SO2 showed no significant difference between the responder and non-responder patients. These results were in agreement with Oliveira-Costa et al. (2012), show that the fluid-induced changes in cardiac output are not reflected at all by the fluid-induced changes SVC SO2.

CVP showed no significant difference between the responder and non-responder patients. This result was in agreement with Marik et al. (2013) who conducted a systematic analysis of 24 studies. Five studies compared CVP with measured circulating blood volume, while the other 19 determined the relationship between CVP (and / or change in CVP) and change in cardiac performance following fluid the poor value of CVP in predicting fluid responsiveness could not be emphasized more. Accordingly, authors recommended that CVP should not be used to make clinical decisions regarding fluid management challenge (Oliveira-Costa et al., 2012), The laboratory data in this study showed a insignificant difference in $\mathrm{Hb}$ level, ALT and AST between responder patients and non-responder, while the other laboratory data show no significant difference. This result was in agreement with (Cherpanath et al., 2016).

VTI at base line and after PLRt showed no significant difference but change of VTI was significantly higher in responders than non-responders with $\mathrm{p}<$ 0.001 . The change of VTI showed area under the curve 0.800 , at the cut off value 3.409.The sensitivity was 90.0 , specificity 
was 70.0, PPV $90.0 \%$, and NPV $70.0 \%$ in predict the responder.

Brun et al. (2012) assessed the usefulness of change of VTI to predict fluid responsiveness in critically ill patients. His study examined patients with SP developed oliguria and spontaneously breathing. VTI after 500cc PLRt showed AUC 0.93 with sensitivity, specificity, PPV and NPV of $75 \%, 100 \%, 100 \%$ and $79 \%$ respectively. In comparison to our results which showed a best cut off value of 3.409 with AUC 0.800 (p<0.001) with sensitivity, specificity, PPV, NPV was $90 \%, 70 \%, 90 \%, 70 \%$ respectively.

In this study, there was no significant difference between the responder and nonresponder patients regarding the inferior vena cava expiratory and inspiratory diameters (IVC Exp \& IVC Insp) in both group's pre and post Passive Leg Rising tests (PLRt). No statistical significant relation between IVCCI pre and post PLRt Pre (IVCCI).

Muller et al. (2012) showed that cIVC cannot predict fluid responsiveness in spontaneously breathing patients with ACF. His study examined patients spontaneously breathing with acute circulatory failure, and showed AUC of the ROC curve for cIVC was 0.77 , with sensitivity, specificity was $70 \%, 80 \%$ respectively. The best cutoff value was $40 \%$. This due to that cIVC was a dynamic preload index. In contrast with findings reported in mechanically ventilated septic patients, dynamic parameters have been shown to be ineffective to predict fluid responsiveness in spontaneous breathing patients (Summers et al., 2013).
Spontaneous ventilation implies a very wide range of breathing patterns. In patients with spontaneous ventilation, respiratory variations are highly variable from one cycle to another in a given patient and between different patients. Then, influence of breathing pattern on cIVC is also variable. These results indirectly confirm that spontaneous breathing is a natural limit for the use of a dynamic parameter; cIVC may be influenced by the magnitude of respiratory movements, especially in the case of dyspnea, a typical feature in patients with circulatory failure and/or shock. The wide range of breathing patterns observed in spontaneously breathing critically ill patients is probably confusing. Kimura et al. (2011) showed that breathing manner significantly affects cIVC in spontaneously breathing volunteers.

\section{CONCLUSION}

Careful management of volume status and fluid administration is an important determinant of outcomes of the critically ill patients. The change in SV displayed predicted fluid responsiveness in shocked not mechanically ventilated patients with an acceptable sensitivity and specificity than IVC collapsibility Index.

\section{REFERENCES}

1. Bendjelid K and Romand J-A. (2003): Fluid responsiveness in mechanically ventilated patients. Intensive Care Medicine, 29 (3): 352360 .

2. Bentzer P, Griesdale DE and Boyd J. (2016): Will This Hemodynamically Unstable Patient Respond to a Bolus of Intravenous Fluids? JAMA, 316 (12):1298-1309.

3. Brun C, Zieleskiewicz L, Textoris J, Muller L, Bellefleur J-P, Antonini F and Leone $M$. (2012): Prediction of fluid responsiveness in 
severe preeclamptic patients with oliguria. Intensive Care Medicine, 39(4): 593-600.

4. Cherpanath T.G., Hirsch A., Geerts B.F., Lagrand W.K., Leeflang M.M. and Schultz M.J. (2016): Predicting fluid responsiveness by passive leg rising: a systematic review and meta- analysis of 23 clinical trials. Crit. Care Med., 44(3):981-991.

5. Hu B, Xiang H, Liang H, Yu L, Xu T and Yang JH. (2013): Assessment effect of central venous pressure in fluid resuscitation in the patients with shock: a multi-center retrospective research. Chin Med. J., 126(10): 1844-1849.

6. Kimura BJ, Dalugdugan R, Gilcrease GW, Phan JN, Showalter BK and Wolfson T. (2011): The effect of breathing manner on inferior vena caval diameter. Eur. J. Echocardiogram, 12(2):120-123.

7. Mackenzie DC and Noble VE. (2014): Assessing volume status and fluid responsiveness in the emergency department. Clin. Exp. Emerg. Med., 1(2): 67-77.

8. Marik P.E., Levitov A., Young A. and Andrews L. (2013): The use of bioreactance and carotid doppler to determine volume responsiveness and blood flow redistribution following passive leg raising in hemodynamically unstable patients. Chest, 143(2): 364-370.

9. Monnet $\mathrm{X}$, Letierce A, Hamzaoui $\mathrm{O}$, Chemla D, AnquelN, Osman D, Richard C and Teboul JL. (2011): Arterial pressure allows monitoring the changes in cardiac output induced by volume expansion but not by norepinephrine. Crit. Care Med., 39(6): 13941399.

10. Muller L, Bobbia X, Toumi M, Louart G, Molinari N and Ragonnet B. (2012): Respiratory variations of inferior vena cava diameter to predict fluid responsiveness in spontaneously breathing patients with acute circulatory failure. Critical care (London, England), 16(5): R188.

11. Oliveira-Costa CD, Friedman G, Vieira SR and Fialkow L. (2012): Pulse pressure variation and prediction of fluid responsiveness in patients ventilated with low tidal volumes. Clinics (Sao Paulo), 67(7): 773-778.

12. Pierrakos C, Velissaris D, Scolletta S, Heenen S, DeBacker D and Vincent JL. (2012): Can changes in arterial pressure be used to detect changes in cardiac index during fluid challenge in patients with septic shock? Intensive Care Med., 38(3): 422-428.

13. Pinsky MR. (2015): Functional haemodynamic monitoring. Curr. Opin. Crit. Care, 20(3): 288-293.

14. Summers R.L., Baker S.D., Sterling S.A., Porter J.M. and Jones A.E. (2013): Characterization of the spectrum of hemodynamic profiles in trauma patients with acute neurogenic shock. Journal of Critical Care, 28(4): 531.e1-531.e5. 
تقييم الاستجابة للسو ائل في مرضي فنثل الدورة الدموية الحاد

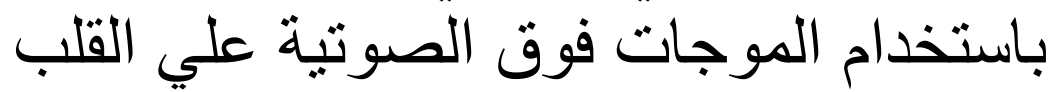

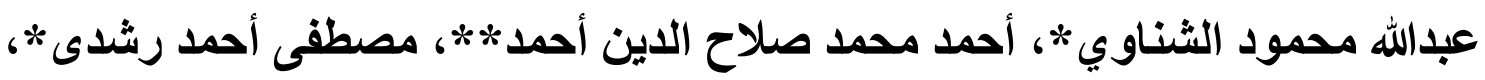

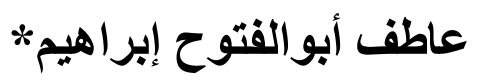

قسمي الأمراض الباطنةّة وأمراض القلب**، كلية الطب، جامعة الأزهر

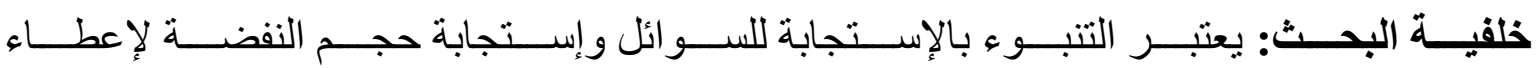

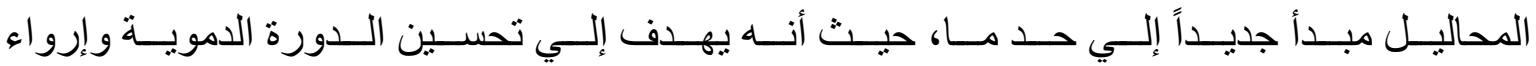

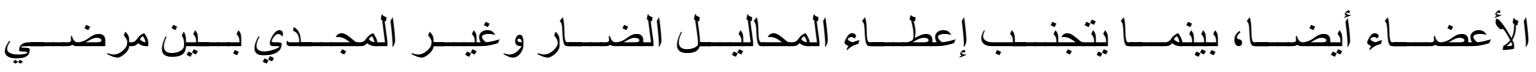

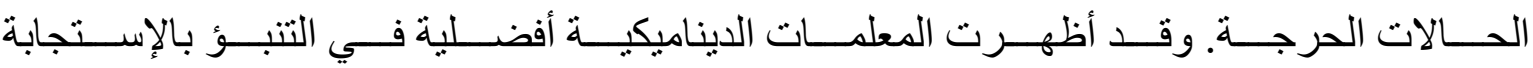

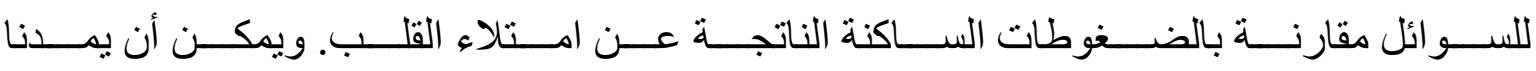

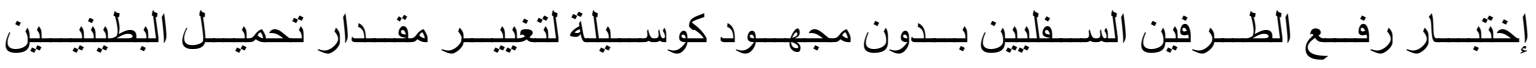

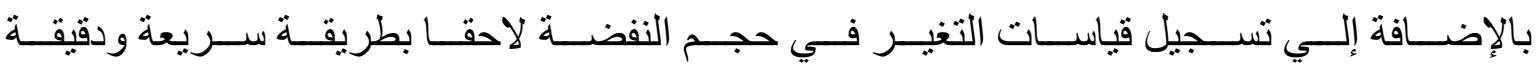
في قيادة عملية التحكم في إعطاء المحاليل لمرضي الحالات الحرجة.

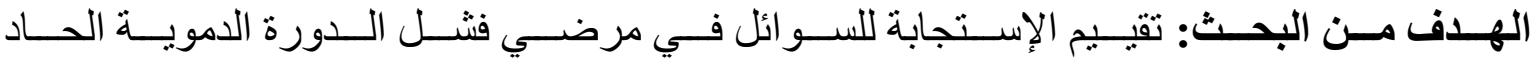

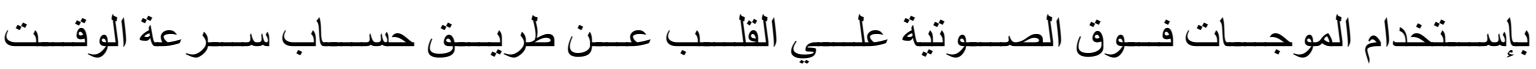
التكاملى لمجرى تدفق البطين الأيسر وقطر الوريد الأجوف السفلى.

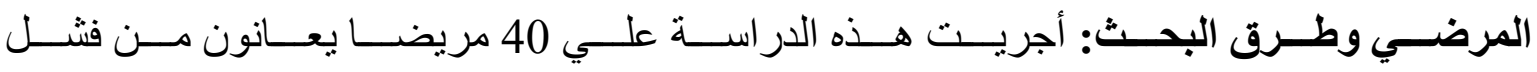

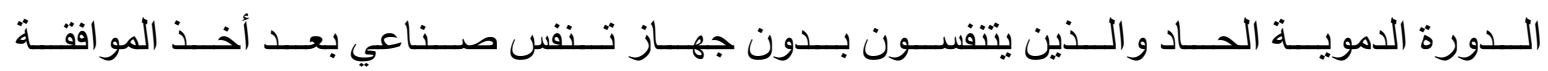

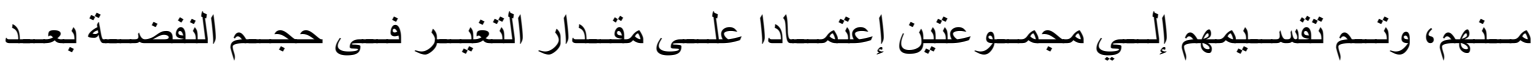
اختبار رفع الطرفين السفليين بدون مجهود:

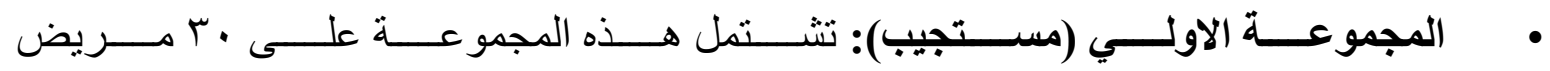

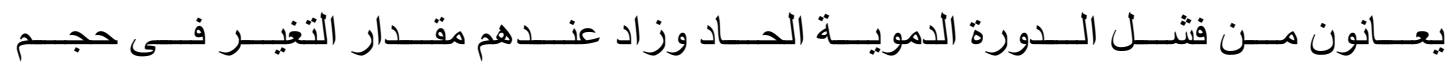

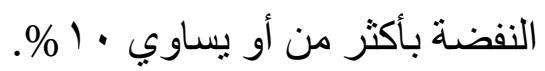




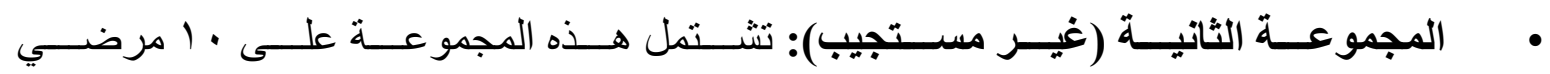

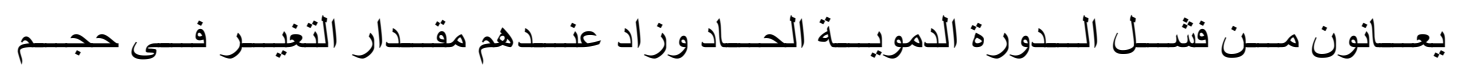

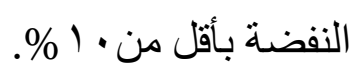

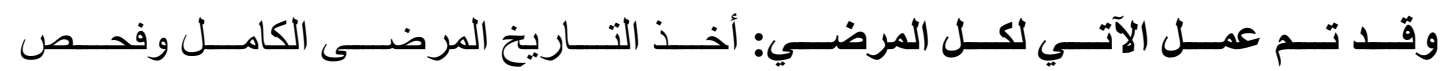

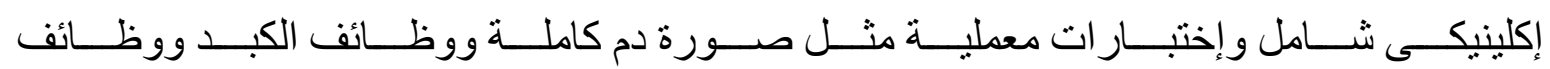

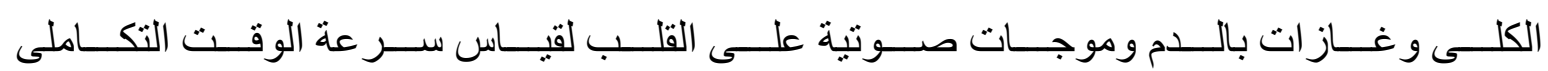

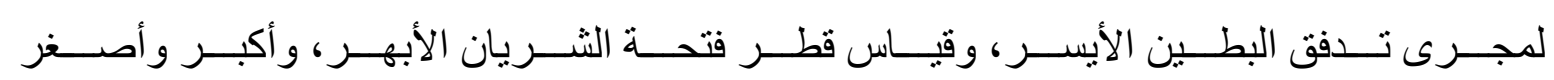

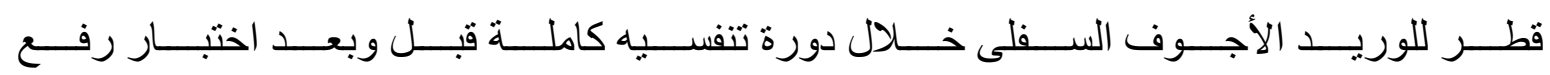

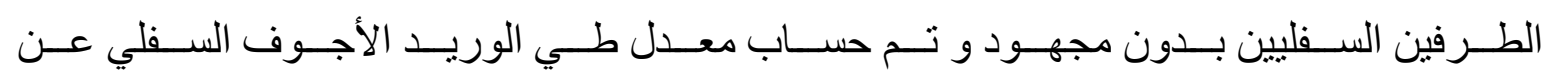

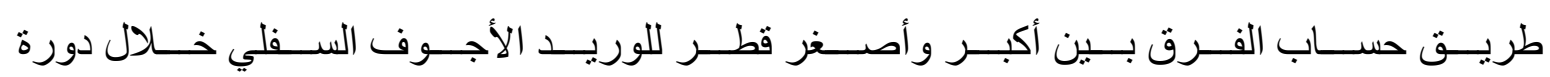

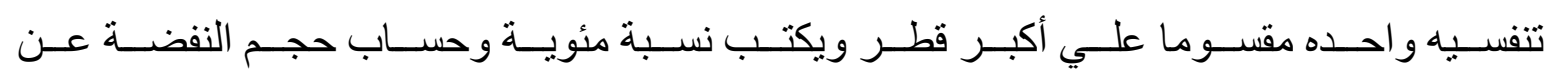

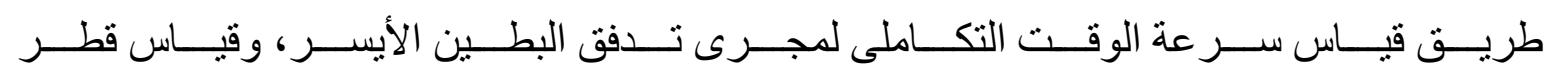
فتحة الشريان الأبهر وتحليل النتائج إحصائياً.

نتائج البحث: عدم وجود فارق ذو دلالة إحصائية بين المجمو عتين بالنسبة للسن و الجنس.

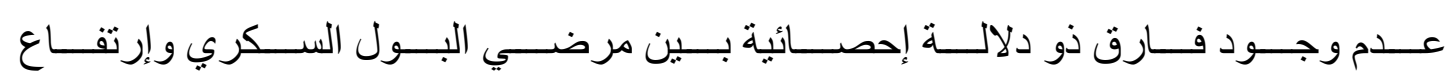
ضغط الدم الثرياني ومرضي الفشل الكلوي المزمن بين المجمو عنين.

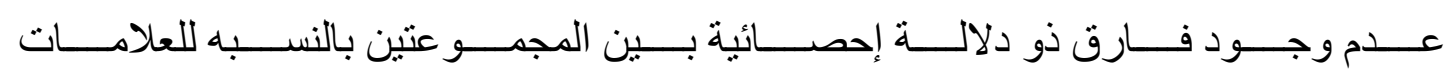
الحيوية وتشمل درجة حرارة الجسم و عدد نبضات القلب و عدد معدل التنفس.

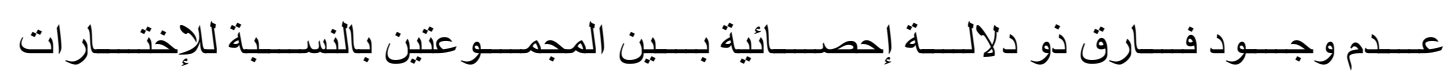
المعملية ما عدا نسبة الهيموجلوبين و إنزيمات الكبد.

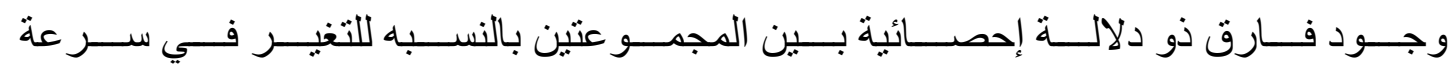

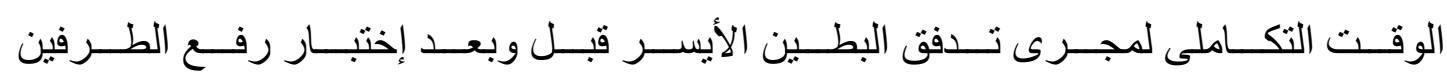

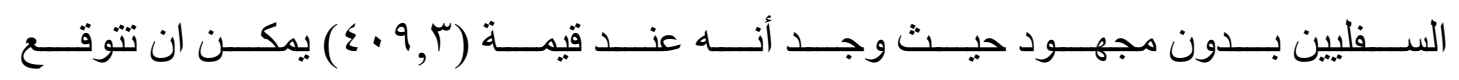

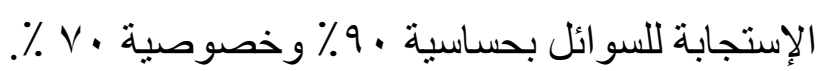




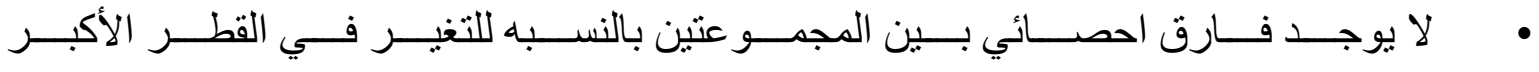

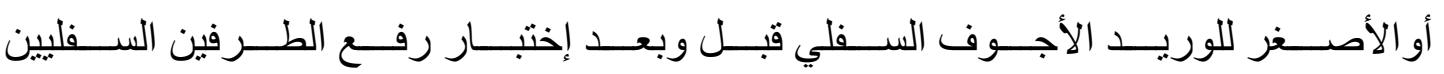

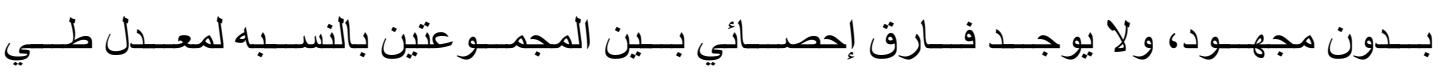
الوريد الأجوف السفلي.

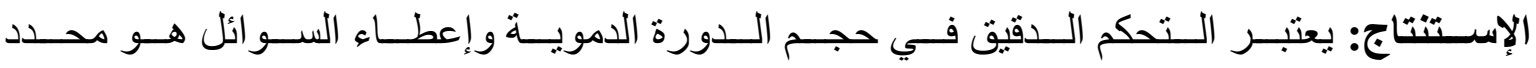

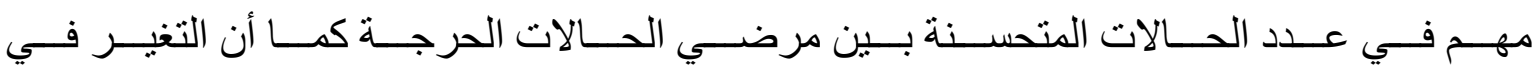

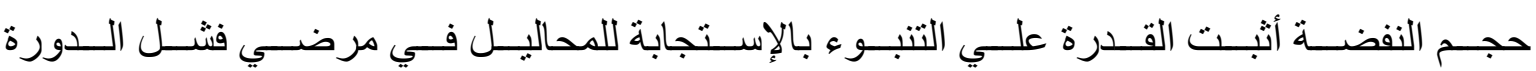

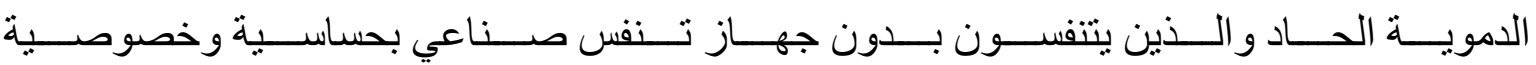
مقبولة أكثر من معدل طي الوريد الأجوف السفلي. 